\title{
Improving the Long-Term Sustainability of Service- Learning Projects: Six Lessons Learned from Early MIT IDEAS Competition Winners
}

\author{
Diana Jue \\ Master in City Planning Candidate \\ Department of Urban Studies and Planning \\ Massachusetts Institute of Technology \\ dmjue@mit.edu
}

\begin{abstract}
An ongoing concern of service-learning projects is whether they can benefit target populations in the long-term. Too often, service-learning projects end before a real deliverable is presented to the community. At MIT, a short history of service-learning projects can be documented through the IDEAS Competition, an annual competition that awards small monetary prizes to student teams that have designed and implemented innovative projects to positively impact underserved communities. This article analyzes how winning projects from the first five IDEAS Competitions either evolved or dissolved. From the experiences and wisdom of these early winners, this article offers six pieces of advice to students and academic institutions seeking to implement service-learning projects: 1) seriously consider implementation aspects from the beginning, 2) be concrete and realistic in the short term, 3) be flexible in the long-term, 4) build a multidisciplinary team, 5) collaborate with a solid community partner, and 6) prepare for continuity.
\end{abstract}

Index Terms - IDEAS Competition, implementation, MIT, sustainability.

\section{INTRODUCTION: RETHINKING COMMUNITY SERVICE THROUGH IDEAS}

Much of MIT's entrepreneurial activity is generated by students who are actively engaged in projects that break through classroom walls and reach to places either locally, such as in Cambridge, MA, or internationally, such as in Cambodia. These projects are becoming increasingly service-oriented, meaning that they attempt to sustainably solve an underserved community's unmet need in collaboration with a local partner. Some of the solutions have ranged from convenient phone-based translation services for recent immigrants to interactive mapmaking for children in Brazil's barrios. As students become more aware of how their technical skills can be applied to causes that can benefit others, their projects push the idea of community service beyond ladling in soup kitchens and pure charity.

At MIT, a popular forum through which students can embark on their own service-oriented projects is the IDEAS Competition. This is an annual competition that awards monetary prizes to student teams that have designed and implemented innovative projects to positively impact underserved communities. Since 2002, over \$264,000 has been awarded to 64 teams in 28 countries (not including 2011's prizes). These winning teams have leveraged their publicity from the IDEAS Competition to raise over $\$ 3.2$ million in follow-on funding. At least three for-profit, five non-profits, and eight technology-transfer initiatives have been established by IDEAS Competition winners with over 10 other teams still working toward these goals ${ }^{\mathrm{i}}$. 
Because the IDEAS Competition is also intended to be an educational activity, of course students benefit from participating in it. They are guaranteed to experience the difficulties and triumphs of working on a team, operate under real world constraints, and have their outlooks and creativities stretched. They may even win a few thousand dollars to implement their projects. However, the IDEAS Competition is also intended to be a community service activity. Whether communities ultimately benefit from the students' efforts in the long-run is not guaranteed. For instance, working with students can strain community organizations' limited resources. Also, as students do not remain students forever, project sustainability is oftentimes called into question.

This article first describes the IDEAS Competition's origins and competition process. It then offers six pieces of advice to students who want to make their student projects sustainable in the field after winning the IDEAS Competition. The wisdom was culled from winners of the first five IDEAS Competition. Their lessons can be summed up as follows: 1) Seriously consider implementation from the beginning, 2) Be concrete and realistic in the short term, 3) Be flexible in the long-term, 4) Build a multidisciplinary team, 5) Collaborate with a solid community partner, and 6) Prepare for continuity.

\section{Creating and Participating in a Service-Learning Competition}

Developed by a team led by Amy Smith of the MIT Edgerton Center (a multidisciplinary center that focuses on hands-on engineering education) and Sally Susnowitz of the MIT Public Service Center, the MIT IDEAS Competition was funded in 2001 by a grant from the d'Arbeloff Fund for Excellence in Education. According to its project summary for the d'Arbeloff Fund, the IDEAS Competition was formed on the foundations of "student enterprise, applied learning, and public service." The competition's name, IDEAS, is an acronym for Innovation, Development, Enterprise, Action, and Service ${ }^{\mathrm{ii}}$.

According to its founders, the greatest motivation to establish the IDEAS Competition was "to inspire students' involvement and interest in the technical aspects of community service work." The competition would "ensure that students learn about the role of innovation in public service and understand the opportunities and responsibilities represented by the cultural, economic, social, and technical issues that face communities locally and internationally." The five main goals of the IDEAS Competition are:

- To promote student inventiveness and entrepreneurship

- To expose students to real-world problem solving

- To provide resources to implement plans and products that meet community needs

- To increase awareness of community needs

- To empower students with the knowledge that they can make a difference in the worldiii

Anyone may participate in the IDEAS Competition, but one-third of all teams must be fulltime MIT students. Teams are formed through engineering design classes, personal connections and shared interests among MIT students, and personal and professional connections between MIT students and off-campus contacts that are either facilitated through the classroom or forged 
casually through students' extracurricular activities. In addition, IDEAS also hosts two Generator Dinners, which are networking events for students who are looking for teams or team members.

Throughout the academic year, teams work with their community partners to define a problem and develop an appropriate solution. Development grants of up to $\$ 1,000$ are available to teams to help them develop prototypes or travel to communities during the semester or the January vacation period. Initial proposals are welcomed on a monthly basis from October to March. IDEAS staff members provide teams with feedback and guidance on their early proposals and can help identify community partners and mentors. Final proposals are due in mid-April, and the Poster and Judging Session takes place in late April. Awards of typically up to $\$ 8,000$ are presented in early May, and winning teams participate in a planning retreat in late May. These teams have up to one year to implement their award money ${ }^{\text {iv }}$.

Since its inception in 2002, the MIT IDEAS Challenge has increased in sponsors and challenges. For example, in December 2006, the Yunus Challenge was launched in collaboration with the MIT International Development Initiative as a component of the MIT IDEAS Competition. Named in honor of Dr. Muhammad Yunus, 2006 Nobel Prize winner, the Yunus challenge invites students to tackle a specific development problem faced by some of the poorest communities in the world. Past challenges have included affordable small-scale energy storage (2009), reducing indoor air pollution (2007), and increasing adherence to tuberculosis drug regiments $(2006)^{\mathrm{v}}$.

Most recently, in honor of MIT's 150th anniversary celebration in 2011, the Public Service Center, MIT150, and the MIT Alumni Association launched the MIT Global Challenge. The Global Challenge invited the worldwide MIT community to collaborate with current MIT students through the IDEAS Competition. It reasoned that the Institute's network of 119,000 alumni, who span across 130 countries, would be useful in defining local problems, connecting teams to resources, fundraising for the IDEAS Competition, and assisting with implementation and scaling ${ }^{\text {vi }}$. The Global Challenge's online platform publicized opportunities for engagement in service projects, including information about sponsored challenges, mentoring opportunities, and online voting on projects. It awarded up to $\$ 15,000$ per team for innovative service projects. Combined, IDEAS and the MIT Global Challenge awarded about $\$ 150,000$ to its winning teams ${ }^{\mathrm{vii}}$.

Of course, winning the IDEAS Competition is just one early step in the timeline of a serious service-learning project. The real difficulties come during implementation, after the excitement, press, and attention have died down.

\section{THE WinNers' CirCle: \\ ADVICE FOR STUDENTS FROM EARLY IDEAS COMPETITION WINNERS}

The following sections are pieces of advice from the winning teams of the first five IDEAS Competitions (2002 through 2006). These teams' service-learning projects achieved varying degrees of success with regards to long-term sustainability. The winning teams' projects were published by the MIT Public Service Center, and their descriptions were listed on the MIT Global Challenge website ${ }^{\text {viii }}$. The MIT Public Service Center provided the author, who is a MIT graduate student, with each teams' winning IDEAS Competition proposals. The author contacted each teams' leader via e-mail. E-mail responses led to semi-structured phone or inperson interviews. More information about these teams can be found in Table 1. 
TABLE 1

MIT IDEAS COMPETITION WINNERS, 2002-2006 ${ }^{\mathrm{IX}}$

\begin{tabular}{|c|c|c|c|}
\hline Team Name & Year & Award & Description \\
\hline $\begin{array}{l}\text { Expediting Access to } \\
\text { Standard Education } \\
\text { (EASE) }\end{array}$ & 2002 & $\$ 2,000$ & $\begin{array}{l}\text { Improve access to basic education in Africa through sponsorship } \\
\text { programs and the establishment of libraries in villages }\end{array}$ \\
\hline $\begin{array}{l}\text { Gasoline Storage Tank } \\
\text { Leak Detection }\end{array}$ & 2002 & $\$ 3,000$ & $\begin{array}{l}\text { Reduce the environmental impact of leaking gasoline storage } \\
\text { tanks by making continuous testing of the monitor wells around } \\
\text { the tanks possible at low cost }\end{array}$ \\
\hline $\begin{array}{l}\text { Innovative Drinking Water } \\
\text { Technology for Bangladesh }\end{array}$ & 2002 & $\$ 5,000$ & $\begin{array}{l}\text { Innovative drinking water treatment design that treats both arsenic } \\
\text { and pathogens simultaneously }\end{array}$ \\
\hline $\begin{array}{l}\text { Passive Incubator for } \\
\text { Premature Infants }\end{array}$ & 2002 & $\$ 5,000$ & $\begin{array}{l}\text { A passive infant incubator independent of electricity, that will be } \\
\text { robust, cheap and sustainable }\end{array}$ \\
\hline Pure Water for Nicaragua & 2002 & $\$ 5,000$ & $\begin{array}{l}\text { A feasible and sustainable solution for potable water accessibility } \\
\text { in rural areas in Nicaragua }\end{array}$ \\
\hline $\begin{array}{l}\text { Salvation Army Data } \\
\text { Collection System }\end{array}$ & 2002 & $\$ 2,000$ & $\begin{array}{l}\text { A system to automate the sign-in and data collection process at the } \\
\text { Salvation Army Cambridge Corps Drop-In Center }\end{array}$ \\
\hline De Barrio A Playa & 2003 & $\$ 5,000$ & $\begin{array}{l}\text { A workshop for young people living in marginal settlements in } \\
\text { Santo Domingo, Dominican Republic }\end{array}$ \\
\hline $\begin{array}{l}\text { Humanitarian Demining } \\
\text { Toolkit }\end{array}$ & 2003 & $\$ 3,000$ & $\begin{array}{l}\text { A low-tech low-cost demining toolkit made from indigenous } \\
\text { materials }\end{array}$ \\
\hline Kinkajou & 2003 & $\$ 5,000$ & A low-cost LED microfilm projector \\
\hline Lumbini Water Solutions & 2003 & $\$ 3,000$ & A household water filter that costs less than $\$ 1$ USD \\
\hline MIT UV Tube Project & 2003 & $\$ 2,000$ & $\begin{array}{l}\text { A simple, low-cost ultraviolet (UV) water disinfection system } \\
\text { constructed from ferro cement }\end{array}$ \\
\hline $\begin{array}{l}\text { Novel Endotracheal Tube } \\
\text { Design (a.k.a. Nerdvana) }\end{array}$ & 2003 & $\$ 2,000$ & $\begin{array}{l}\text { Ameliorate the complications of the present inflatable cuffs } \\
\text { inflated at the trachea by alleviating the high constant pressure and } \\
\text { placing it with a low-pressure system }\end{array}$ \\
\hline $\begin{array}{l}\text { Science Education in } \\
\text { Pakistan Group }\end{array}$ & 2003 & $\$ 3,000$ & $\begin{array}{l}\text { Provide access to scientific equipment and enable students in } \\
\text { villages in Pakistan to perform experiments using a mobile science } \\
\text { lab }\end{array}$ \\
\hline Vendenergy & 2003 & $\$ 3,000$ & $\begin{array}{l}\text { A machine that takes the batteries in, cleans, and recharges them, } \\
\text { and vends a recharged battery "instantly" at a much lower cost } \\
\text { than a new physical battery }\end{array}$ \\
\hline Chlorination in Honduras & 2004 & $\$ 5,000$ & $\begin{array}{l}\text { A system that produces a constant chlorine dosage without any } \\
\text { moving parts or increased maintenance }\end{array}$ \\
\hline $\begin{array}{l}\text { Sistema de Alerta } \\
\text { Temprana }\end{array}$ & 2004 & $\$ 3,000$ & $\begin{array}{l}\text { Automated early warning system that will provide } 24 \text {-hour } \\
\text { monitoring of the current river and weather conditions in the Rio } \\
\text { Aguan Basin }\end{array}$ \\
\hline Speakeasy & 2004 & $\$ 2,000$ & $\begin{array}{l}\text { A community-based telephone service that allows immigrants to } \\
\text { establish conference calls with social service agencies and } \\
\text { volunteer "guides" }\end{array}$ \\
\hline Test Water Cheap & 2004 & $\$ 5,000$ & Device to test local drinking water frequently and inexpensively \\
\hline WearAnEye & 2004 & $\$ 2,000$ & $\begin{array}{l}\text { A system which will make use of current computer vision } \\
\text { technology to aid blind or visually impaired pedestrians }\end{array}$ \\
\hline Bicilavadora & 2005 & $\$ 5,000$ & $\begin{array}{l}\text { A low cost, pedal-powered washing machine that is designed } \\
\text { around readily available parts }\end{array}$ \\
\hline MANTRA & 2005 & $\$ 2,000$ & $\begin{array}{l}\text { An internet program for people living in rural areas for the } \\
\text { purpose of a computerized medical evaluation }\end{array}$ \\
\hline $\begin{array}{l}\text { Mozambique } \\
\text { Environmental Sanitation } \\
\text { Initiative }\end{array}$ & 2005 & $\$ 3,000$ & Innovations in environmental management and sanitation \\
\hline Parabolic Power II & 2005 & $\$ 2,000$ & Solar concentrator device that heats, a working fluid for energy \\
\hline
\end{tabular}




\begin{tabular}{|c|c|c|c|}
\hline Robopsy & 2005 & $\$ 5,000$ & $\begin{array}{l}\text { transfer to multiple, user-specified applications } \\
\text { A suite of low cost, image-guided, patient-friendly } \\
\text { electromechanical tools that enable more accurate diagnosis and } \\
\text { treatment of disease }\end{array}$ \\
\hline $\begin{array}{l}\text { Solar Water Disinfection } \\
\text { Device }\end{array}$ & 2005 & $\$ 2,000$ & $\begin{array}{l}\text { An inexpensive solar disinfection device that is easily transported } \\
\text { in bulk to distribution sites, quick to disinfect water, and easy to } \\
\text { use and maintain in the areas of need }\end{array}$ \\
\hline VacPac & 2005 & $\$ 3,000$ & $\begin{array}{l}\text { Versatile, off-grid ready refrigerator for vaccine preservation and } \\
\text { transportation }\end{array}$ \\
\hline Wider Reach & 2005 & $\$ 2,000$ & Wireless marketplace for the developing world \\
\hline Aerovax & 2006 & $\$ 7,500$ & $\begin{array}{l}\text { Innovative and low-cost last-mile solutions for vaccinating } \\
\text { developing populations against deadly infectious diseases }\end{array}$ \\
\hline AllHeal & 2006 & $\$ 5,000$ & $\begin{array}{l}\text { Technology to heal cases of chronic, and potentially debilitating, } \\
\text { wounds }\end{array}$ \\
\hline FirstStepCoral & 2006 & $\$ 7,500$ & $\begin{array}{l}\text { Combine the new Gorlov turbine to harness unexploited tidal- } \\
\text { energy to grow Biorock assisted coral reefs }\end{array}$ \\
\hline Peanut Revolution & 2006 & $\$ 5,000$ & An upgradable version of improved the hand peanut sheller \\
\hline Rowing Wheelchair & 2006 & $\$ 2,500$ & $\begin{array}{l}\text { Rowchair better enables the user to tackle steep slopes and rugged } \\
\text { terrain, and offers more efficient propulsion over longer distances }\end{array}$ \\
\hline SafePilot & 2006 & $\$ 2,500$ & $\begin{array}{l}\text { Low-cost extension to existing canes that conveys additional } \\
\text { information to the user in an unobtrusive manner }\end{array}$ \\
\hline TurnPure & 2006 & $\$ 5,000$ & $\begin{array}{l}\text { Technology that can rapidly and effectively purify water without } \\
\text { using chemicals or battery power }\end{array}$ \\
\hline
\end{tabular}

\section{Advice \#1: Seriously Consider Long-Term Implementation from the Beginning}

Implementation should be considered with the development of an idea. At the very least, this includes identifying an appropriate community partner for a new idea (or preferably having a problem identified by a community partner), budgeting the competition prize money, and scheduling when and where the team will use the prize money during the following year. On a more advanced level, teams should frame their projects for the long-term. For instance, teams whose projects continued for years after winning the IDEAS Competition saw the IDEAS Competition as one small source of funding. They were able to leverage their victory to secure more press and more funding. Additionally, these teams formed the necessary organizations whether they were student groups, lab groups, non-profit organizations, or businesses - to continue implementation after the teams' original members graduated.

One example is the MIT UV-Tube Project, a simple, low-cost ultraviolet water disinfection system, and the 2003 IDEAS Competition Winner. The IDEAS project proposed to implement the UV-Tube in Haiti as part of a new "brainstorming technology center" designed to promote simple environmental and health technologies. The IDEAS grant was the first grant received by the student team, which was located at the University of California, Berkeley, and included one MIT team member. From the beginning, it was seen as one small source of funding for a much larger scale project. The IDEAS grant helped set up the technology center, teach local community members different methods of water disinfection, and build the first UV-Tube. However, the UV-Tube has not been successfully brought to Haiti due to a number of constraints. Despite this apparent setback, the UV-Tube team at UC Berkeley continued winning grants, and old and new team members set non-profit organizations in Mexico and Haiti to work on issues inspired by their project. 
Another example is Aerovax, a low-cost, last-mile solution for vaccinating developing populations against infectious diseases and the 2006 IDEAS Competition winner. In recent years, more and more teams have participated in both the IDEAS Competition as well as the MIT 100K Competition during the same year. Aerovax was a finalist in the MIT 100K Business Plan Competition (Development Track) in which it was forced to consider how to implement their product through a sustainable business. For the team, the publicity received from the IDEAS Competition and the $100 \mathrm{~K}$ Competition helped them secure a pro-bono contract with a big law firm and another grant from the National Institute of Health through Harvard University. Right now, the product is awaiting approval from the World Health Organization so that Doctors Without Borders can begin implementing it.

In a handful of cases, winning teams fizzled out after the competition. For example, Safe Pilot, a low-cost extension to existing canes that conveys additional information to the user and 2006 IDEAS Competition winner, did not receive or seek additional funding after winning. Some of the money was used to buy components and to experiment with different models, but actual testing and implementation with blind users was never seriously pursued because the task was difficult and the team was small. The community partner ended up losing interest as well. In another example, TurnPure, a technology that rapidly and effectively purifies water without using chemicals or battery power, and a 2006 IDEAS Competition winner, and MIT Soldier Design Competition winner, is currently on hold. No organizations were set up to continue the project after the team won, and the team members went their separate ways after graduation. In this project, planning for long-term implementation was necessary because the product was still relatively underdeveloped when it won. It needed plans for continued funding and manpower to support research and development and eventual implementation through the market.

\section{Advice \#2: Be Concrete and Realistic in the Short Term}

Participating in the IDEAS Competition requires creativity, but that creativity should be rooted in reality. Yes, it is important to consider long-term implementation, but in the short run, teams should focus on producing a deliverable that benefits the target audience. It is too easy to be overambitious when writing a project proposal because implementation is an entirely different ordeal that requires concrete, doable steps of action. IDEAS Competition award money is available for one year, so teams should be realistic and reasonable when proposing timelines and budgets for this year.

In order for teams' solutions to be realistic, they should thoroughly understand the problems in their target communities, the potential constraints and obstacles, and their own technologies. They also need to be realistic about their own commitment levels, whether they are onboard for the semester, the summer, or the long haul. Since these projects involve additional stakeholders particularly the community partner - not following through has real consequences. According to the team leader of Sistema de Alerta Temprana, an early flood warning system in Honduras and 2004 IDEAS Competition winner, the project faced difficulties in implementation for two reasons: 1) the team members did not actually understand the problem and 2) they were too ambitious with their solution. A misunderstanding of the community's water issues led to the development of inappropriate hardware, which pushed their schedule far behind. A second assessment trip was necessary, and the final design was finished a year late. By this point, the team leader was working alone on the project as a part of her $\mathrm{PhD}$ dissertation; her team members who had committed to the project early on left the project within one month. 
In some cases, early IDEAS Competition winners appeared to be selected based on the technology and not so much the immediate implementation, such as Nerdvana, a novel endotracheal tube design and 2003 IDEAS Competition winner. Nerdvana was essentially a oneperson undergraduate research project. Although the student won additional business plan competitions, implementation through commercial development never occurred because the project remained stuck in research and development. Like in the previously mentioned team, TurnPure, Nerdvana had no structures in place to secure funding and manpower for ongoing R\&D and future implementation. Additionally, both projects' team members knew from the beginning that commercialization would be difficult in the short term because: 1) they were still doing R\&D and 2) entering the market for their respective products was known to be difficult. In the end, both products were tinkered with after winning the IDEAS Competition, but nothing was actually delivered.

\section{Advice \#3: Be Flexible in the Long-Term}

A common piece of advice delivered by members of winning IDEAS Competition teams is to be flexible with long-term plans. Sometimes a technology might not work as well as expected. Sometimes the community partner presents new needs or has limited capabilities. It is necessary to: 1) bring an appropriate and functional solution to the collaboration while 2) flexibly working with feedback from the community partner, which may not be forthcoming.

For example, the team behind Chlorination in Honduras, a 2004 IDEAS Competition winner that made community drinking water safe via chlorination, discovered the technical insufficiencies of its solution after winning the IDEAS Competition. After experimenting with a new design in Cambridge for about six months, the team abandoned its new, high-tech, automatic solution that was not working and returned to its original, simpler, manual design, which was working. From there, the team focused less on the design and more on the implementation. Because they wanted to give the community a functional product - even if it was not the high-tech solution they had intended, they were able to leave their idea behind.

\section{Advice \#4: Build a Multidisciplinary Team}

In the words of one winning IDEAS team member who continued his education at Stanford University and became heavily involved in designing and disseminating technologies that create human impact, "If innovations will succeed in the world, then you need to have people who know how to work on a team." In his experiences on both coasts, he recognized that the teams that made the biggest differences in communities were those that were interdisciplinary (with both engineers and entrepreneurs), worked well together, and trusted each other.

Collaborative and multidisciplinary teams play an important role in implementation. If team members come from similar backgrounds, it is more likely that they will only focus on one aspect of the project. As previously explained, some IDEAS Competition winners were so concerned with innovation that they were not interested, or they did not know how, to successfully implement their projects. As the IDEAS Competition developed, participating teams became increasingly multidisciplinary. Proposals now require biographies from each team member detailing how he or she contributes to the development and implementation of the project. Team dynamics tended to be a common issue for many early IDEAS Competition teams, and in many cases, long-term implementation fell on the shoulders of one team member. While 
commitment of a team leader is necessary, the team leader still requires teammates to make the project successful during execution.

For example, members of the Passive Incubator for Premature Infants team, which won the IDEAS Competition in 2002, split due to some trust and accountability concerns over the technology. One member was still working on the incubator even though other team members thought that the project was handed off. For the team behind Innovative Drinking Water, a winner of the first IDEAS Competition and developer of a simple arsenic water filter for use in Nepal, it also experienced unfortunate team dynamics that affected how the prize money was utilized. The team member who was in charge of implementation had a different plan from his teammates, and after they won, he insisted on carrying out his plan alone using a portion of the prize money. His teammates conceded by giving him 20 percent of their award, which he essentially wasted because his plans never evolved. However, despite this small debacle, the project was able to make an impact because the very committed team leader literally packed his bags, moved to Nepal with a grant from the World Bank, and implemented the water filter while solidifying connections with the community partner, who carried out the project in the long run.

Contrast these teams with more recent IDEAS Competition entrants such as Global Cycle Solutions (GCS) was a 2009 IDEAS Competition entrant and 2009 MIT \$100K Development Track winner. GCS was started at MIT by a group of undergraduate, graduate, and MBA students and addresses rural issues in Tanzania through pedal-powered solutions. The current 13person team consists of current MIT students, MIT students who have graduated, and local Tanzanian hires that come from a range of engineering and business backgrounds. At least five of the team members are currently working and living in Tanzania, including the President and CEO, and an MIT graduate, while others are working stateside. The geographically spread out, multidisciplinary team has made GCS a relative success compared with other student serviceprojects.

\section{Advice \#4: Collaborate with a Solid Community Partner}

Service-learning projects work when the community partner is interested in the project and established enough to provide support. Depending on the team's innovation and implementation plan, the community partner can play a number of roles. For student teams developing solutions for community partners, community partners are simultaneously a client and, in many cases, a co-developer of the technology. For student teams that seek to establish their own organizations, or development and distribute their invention, community partners provide an undisputed understanding of local conditions and real connections to people who will benefit from the innovation.

If the student team plans to disseminate the innovation through the community partner, then a capable, committed community partner is key to long-term project self-sustainability. For example, the technology created through the Innovative Drinking Water Project is still being disseminated by the project's community partner, a scientific nongovernmental organization, even though the student team leader left the country, and Nepal's political situation prevented new students from coming into the country. In another example, Chlorination in Honduras' community partner actually improved on the system while the students were in the USA. From the student teams' training, they were able to teach other communities how to construct water chlorination systems from scratch. At this point, two and a half years after winning the IDEAS 
Competition, the project became self-sustainable, and the Chlorination in Honduras team decided to pull out.

While good community partners can successfully implement a project, not so good community partners - or not having an advocate for the project within the organization - can lead to the end of a project. For example, the Salvation Army worker who initiated the Salvation Army Data Collection System, which automated the sign-in and data collection process at the Cambridge Corps Drop-In Center in Massachusetts, was not yet an officer when the student team won the IDEAS Competition in 2002. This worker left Cambridge for officer training but was not posted back to the Cambridge shelter, so the initial vision of collecting data on homeless shelter clients and bringing the data to the organization's headquarters was never realized. In another example, Sistem de Alerta Temprana worked with a community partner that had internal issues. New policies led to the resignation of the organization's director, who was the student team's main point person. His departure made it difficult for the team to work with the community partner because the company started focusing less on engineering and more on agriculture. The project reached a point where it was ready for implementation, but there was no funding, plan, or organization to implement it. By the time the Honduran coup d'etat occurred in 2009 , there were other issues to worry about.

\section{Advice \#5: Prepare for Continuity}

Many early IDEAS Competition winning projects lost steam after the first generation of student team members graduated. Because service-learning projects are also benefiting community partners, their discontinuation could be harmful or, at least, a waste of community partners' time and energy if nothing is delivered. Student teams should prepare for their projects' continuity through a combination of: 1) working with or creating organizations to facilitate the participation of new students and the acquisition of new funds, 2) maintaining close relationships with partner organizations, and 3) technology transferring to new students or to partner organizations. The academic institution where these service-learning projects take place can play a large and active role in the continuity of projects.

At MIT, IDEAS Competition winners who had direct relationships with classes or professors benefited from the institutional support. A popular lecturer in the Department of Civil Engineering supported Innovative Drinking Water by helping to write proposals to secure funding and sending academic and thesis advisees to work on the project. Chlorination in Honduras began as a project for D-Lab (Development Lab), a course that introduces students to innovating solutions for the developing world. Chlorination in Honduras' team leader became the trip leader for subsequent trips to Honduras, and D-Lab was able to maintain a close relationship with the community partner. The main project behind the MIT UV-Tube Project was at UC Berkeley, where ownership of the project was shared among multiple generations of students and professors who worked on it. Because the project was always open to improved design ideas while requiring lab and field-testing of old designs, there were always new ways for students to become involved. It was relatively easy for students to join the project because many other students and professors were working on it.

If a student team knows that it will not be the implementers of the project in the very longrun, this should be noted from the beginning and accounted for through extensive, formal documentation of the innovation, the community context, and any potential obstacles. These teams should be ready to transfer information and technology to the community partner or to 
other students who will continue the project. Dead projects should be promoted by the institution if there is still community interest. Students often create beneficial technologies that fail to leave the institution because the original student inventors never implemented it. Therefore no new students continued developing it or tried taking it to the field because it was not advertised, or there was no documentation of the technology that would allow new students to easily continue the project.

Through the recently established Technology Dissemination Fellowship, the MIT International Development Initiative is attempting to formalize a technology transfer process between students and eventually, to multiple community partners who can benefit from the same innovation. Whether students are useful as agents of technology transfer to community partners is yet to be determined, since their time in the field to learn the context, adapt the technology, teach the technology, and build relationships is extremely limited. A more permanent, institutional liaison, who maintains strong connections between students and community partners by keeping communication channels open when students are not in the field, may be a key driver of technology transfer.

\section{CONCLUSION: THE BIG IDEA BEHIND IDEAS?}

Advice for the implementation of student service-learning projects can be culled from winners of the first five MIT IDEAS Competitions and be summarized as follows: 1) Seriously consider implementation from the beginning, 2) Be concrete and realistic in the short term, 3) Be flexible in the long-term, 4) Build a multidisciplinary team, 5) Collaborate with a solid community partner, and 6) Prepare for continuity. Having completed its tenth competition in the 2010-2011 academic year, the MIT IDEAS Competition has already learned much from its past winners. As a result, the competition's application and judging encourage student teams to think more seriously about long-term implementation. Recent teams have also benefited from the increasingly popular trend of social entrepreneurship and the increased availability of funding for engineering projects with social missions.

This discussion about the IDEAS Competition's winners requires returning to core questions regarding the nature of service-learning. Is the primary objective of service-learning to highlight novel ideas and inventions, to provide students with learning opportunities, or to create positive sustainable impact in communities? Are student inventors the best implementers, or should innovations be disseminated by partner organizations, other students with more appropriate skills, or small and growing enterprises? The answers to these questions affect how students should approach service-based projects and how institutions should formalize the processes of identifying and implementing these inventions. By doing so, students' innovations may have a greater chance of benefiting the people they were intended to help. 


\section{REFERENCES}

Lars Hasselblad Torres. 2010. Invention as Public Service at MIT. October. http://www.slideshare.net/mitideas/invention-as-public-service-at-mit.

ii d'Arbeloff Fund. 2011. d'Arbeloff Fund for Excellence in Education: Past Projects. d'Arbeloff Fund for Excellence in Education. February 15. http://web.mit.edu/darbeloff/past.html.

iii Amy Smith, Amy Banzaert, and Sally Susnowitz. 2003. The MIT IDEAS Competition: Promoting Innovation for Public Service. In Proceedings. Boulder, Colorado, November 5.

iv MIT Public Service Center. 2010. IDEAS Competition - MIT Public Service Center. MIT Public Service Center. http://web.mit.edu/mitpsc/resources/ideas-competition/index.html.

$v$ Yunus Centre. 2009. Yunus Centre: The Yunus Challenge. Yunus Centre.

v http://www.muhammadyunus.org/About/the-yunus-challenge/.

vi Torres. 2010. Invention as Public Service at MIT

vii MIT Public Service Center. 2010. IDEAS Competition - MIT Public Service Center.

viii MIT Global Challenge. 2011. Past Teams | MIT Global Challenge. MIT Global Challenge. http://globalchallenge.mit.edu/teams/winners.MIT

ix MIT Global Challenge. 2011. Past Teams | MIT Global Challenge. 